\title{
Intertrial reinforcement and the partial reinforcement effect as a function of number of training trials
}

KENNETH W. SPENCE, JOHN R. PLATT AND ROY MATSUMOTO

UNIVERSITY OF TEXAS

days. Every 3 min. each $\mathrm{S}$ was removed and immediately placed back into the apparatus at one of five selected points such that on a given day it entered the apparatus at each of the points in a predetermined random order.

The experimental procedure consisted of three successive sequences of conditioning trials, each of which was followed by 15 extinction trials. In the first acquisition period nine trials were given on the first experimental day, followed by $1 \mathrm{R}$ and $15 \mathrm{~N}$ trials on Day 2. Three days later, six days of nine training trials each were given, followed on Day 11 by $1 \mathrm{R}$ and $15 \mathrm{~N}$ trials. On Day 14 a third six-day training period began, which was again followed by $1 \mathrm{R}$ and $15 \mathrm{~N}$ trials on Day 20. All training trials involved $30 \mathrm{sec}$. in the goal box and then a 30-sec. intertrial interval (ITI). On trials followed by ITR, the first half of the ITI was spent in the confinement and the second half in the baited goal box. On all other trials the entire ITI was spent in the confinement box. All extinction trials were followed by $15 \mathrm{sec}$. in the unbaited goal box and then a 30-sec. ITI in the confinement box. In extinction any $\mathrm{S}$ who did not traverse the entire runway within $60 \mathrm{sec}$. was removed to the confinement box and its time for that trial was recorded as $60 \mathrm{sec}$. Only five Ss reached this criterion.

Ss were assigned randomly to three groups, which differed only in respect to their treatment on training trials. On such trials Group C (continuous) was always reinforced by a $30-\mathrm{sec}$. exposure to wet mash. It was given ITR after the second, fifth and eighth trials of each training day. The partially reinforced groups (PN and PR) received five $\mathrm{R}$ and four $\mathrm{N}$ trials on each training day according to the schedule RNRNNRRNR. Group PN received ITR on the same schedule as C, while PR was given ITR after the third, sixth and ninth trials of each training day. Thus, PR received ITR after $\mathrm{R}$ trials while $\mathrm{PN}$ always received it after $\mathrm{N}$ trials that preceded $R$ trials. There were $16 \mathrm{Ss}$ in each group following the second extinction period. Two Ss in Group C were lost. Their data for the first two extinction periods was retained, however, since it was homogeneous with the data of the rest of Group C.

\section{Results}

Individual starting, running and goal times were converted to speeds (ft/sec.). Although the results for the three measures differed somewhat, they showed more or less the same trends. For comparison purposes the running speed data are presented since Black \& Spence and McCain reported this measure. The 


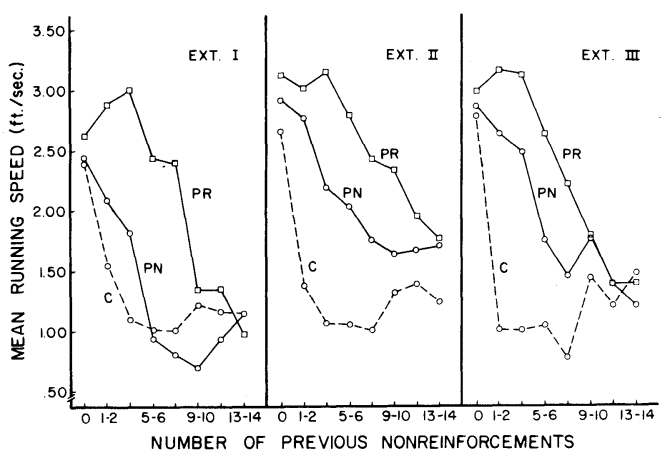

Fig. 1. Mean running speeds in three successive extinctions.

studies from Capaldi's laboratory involved what amounted to a combination of all three measures. Figure 1 shows the running speed curves for the three extinction periods. The results in the first extinction replicated the findings of McCain in showing the PRE effect in Group PR and also in the elimination of this effect when ITR was given following $\mathrm{N}$ trials as in Group PN.

Since in several instances the acquisition performance levels for the three groups differed significantly, a rate-of-extinction statistic (Anderson, 1963, equation 5) was calculated for each $\mathrm{S}$, on each speed measure and in each extinction sequence. For purposes of this calculation, the asymptotes of extinction were estimated to be $.10, .60$, and $.40 \mathrm{ft} / \mathrm{sec}$. for starting, running and goal speeds, respectively. A repeated-measures analysis of variance was carried out separately on the rate indices for each of the three speed measures. The levels of the within variable were the successive extinctions. In the case of running speed, Groups $(\mathrm{F}=23.31 ; \mathrm{df}=2.45 ; \mathrm{p}<.001)$ and Extinctions $(\mathrm{F}=5.50$; $\mathrm{df}=2,88 ; \mathrm{p}<.01$ ) were significant, while the interaction was not. Multiple range tests applied to the Groups variable in the first extinction revealed that Group PR extinguished significantly slower than both Groups PN and $\mathrm{C}(\mathrm{p}</ 001)$, whereas the latter did not differ from each other $(p>.10)$.

In the second and third extinction it is apparent that Group PN became increasingly more resistant to extinction. Even in the second period it is significantly more resistant than Group $C(p<.05)$ while in the third period its rate of extinction did not differ significantly from that of Group PR ( $p>.10)$. Multiple range tests of the running-speed rates for the successive extinctions indicated that the extinction rate of Group PN became significantly slower, whereas there were no significant differences in the case of Groups $C$ and PR. The finding of this final extinction period thus agreed with Black and Spence's results in showing no effect of ITR on PRE after a large number of acquisition trials (120).

In respect to starting speeds, Groups $(F=94.44$; $\mathrm{df}=2,45 ; \mathrm{p}<.001)$ and Extinctions $(\mathrm{F}=17.59 ; \mathrm{df}=2,88$; $\mathrm{p}<.001$ ) were significant while the interaction only approached significance $(\mathrm{F}=2.07 ; \mathrm{df}=4,88 ; \mathrm{p}<.10)$. Multiple range tests indicated that in each of the three extinctions, PR extinguished slower than PN, which extinguished slower than $\mathrm{C}$, with all differences significant beyond the .001 level. In the case of goal-speed rates, neither Groups, Extinctions nor the interactions were significant.

\section{Diseussion}

The results of the first extinction not only confirm the findings of McCain $(1964 ; 1965)$ but also add support to the generalization that the number of training trials required to produce PRE is inversely related to the magnitude of the reward employed. The finding of PRE with so few training trials and its elimination by the ITR procedure also lend further support to the Hullian stimulus-aftereffects hypothesis as modified by Capaldi and his associates. Within the framework of this hypothesis the decreasing effectiveness of ITR on extinction rate with increased amount of training might be accounted for in terms of discrimination by the Ss of the stimulus aftereffects of $\mathrm{R}$ and ITR trials with the consequence that ITR is no longer capable of replacing $S^{N}$ with the aftereffect of reinforcement $\left(S^{R}\right)$. Capaldi and Spivey's finding that the magnitude of the effect of ITR on PRE was less the greater the discriminability of the ITR box and the goal box indicates the effects of such differential conditioning. Another possible factor that might account for this decreased effectiveness of ITR with a large number of training trials is suggested by the frustration theory of Amsel (1958) and Spence (1960). After extended training the locomotor response would becorne strongly conditioned to the stimulus consequences $\left(s_{f}\right)$ of anticipatory frustration responses that occur in the runway. This should have the effect of increasing the resistance to extinction of such groups as PN and PR, regardless of ITR.

\section{References}

Anderson, N. H. Comparison of different populations: Resistance to extinction and transfer. Psychol. Rev., 1963, 70, 162-179.

Amsel, A. The role of frustrative nonreward in noncontinuous reward situations. Psychol. Bull., 1958, 55, 102-119.

Black, R. W., \& Spence, K. W. Effects of intertrial reinforcement on resistance to extinction following extended training. $J$. exp. Psychol., in press

Capaldi, E. J., Hart, D., \& Stanley, L. R. Effects of intertrial reinforcement on the aftereffect of nonreinforcement and resistance to extinction. J. exp. Psychol., 1963, 65, 70-74.

Capaldi, E. J., \& Spivey, J. E. Effects of goal box similarity on the aftereffect of nonreinforcement and resistance to extinction. $J$. exp. Psychol., 1963, 66, 461-465

McCain, G. The effect of intertrial reinforcement on resistance to extinction. Paper read at Midwestern Psychological Association, St. Louis, April, 1964.

McCain, G. Partial reinforcement with a small number of trials: Performance in extinction. Psychon. Sci., 1965, 2, 131-132.

Spence, K. W. Behavior theory and learning. Englewood Cliffs, N. J.: Prentice-Hall, 1960.

\section{Note}

1. The present experiment was conducted at the State University of Iowa. The last author is now at Hayward College. 